\title{
Reflexões em torno do Grande Sertão: Veredas, de Guimarães Rosa
}

Kathrin Holzermayr Rosenfield I UFRGS

Resumo: Reflexões em torno do Grande sertão: veredas, de Guimarães Rosa, com abordagens que privilegiam gênero literário, engajamento político, adesão filosófica.

Palavras-chave: reflexões literárias, filosóficas, políticas.

Entre as questões que mobilizam os leitores de G. Rosa, apenas uma começou a se resolver razoavelmente: Grande Sertão: Veredas não é mais considerado um romance "ilegível", embora nunca se tornou popular no sentido da preferência do grande público. No entanto, há outras questões sem nenhum consenso - e isso é um bom sinal, porque revela a complexidade da obra. Rosa foi elogiado (e de perspectivas bem diversas, como mostram os livros de Hansen e Fantini) como obra aberta que rompe com as fronteiras e explora inúmeras margens, tanto ao nível da ficção como da existência humana. Mas também já foi criticado por ter escrito uma obra regional, de ter assumido uma atitude regressiva, criando uma estética da pobreza (segundo Mainardi). A ardilosa integração do elemento popular, que media estratos heterogêneos 
da cultura, é ela vício ou virtude? Justifica a abertura Rosiana a comparação com Joyce? Antes de entrar nessa questão, mencionemos ainda um outro ponto importante - a questão de saber se Rosa foi engajado ou omisso na elaboração dos problemas políticos, religiosos e sociais do seu país, ou se ele, junto com sua crítica, não são por demais mistificadores e metafísicos. Todas essas questões estão interligadas, uma deve dever à seguinte.

Para começar, é preciso constatar que, por mais aberta e poligonal que seja a obra de Rosa, ele escolheu o universo - limitado - do sertão que não é um universo romanesco, mas pende bem mais para os gêneros do epigrama, da epopéia e da lenda. Isso é um sinal que cabe meditar menos sobre analogias joyceanas de Grande Sertão:Veredas do que sobre suas diferenças. Rosa usa a ruminação reflexiva ao seu modo, com o vago objetivo de criar uma narrativa predominantemente lírica (e esta é uma grande diferença para com Joyce) que traz à tona um fundo emocional, fundamental da mentalidade luso-brasileira. O verniz, a suferfície moderna e joyceana criam um tênue estranhamento que prepara outros deslocamentos da temática regional e da saudade. Isso já nos leva ao segundo problema - o do regionalismo, tão criticado como jogo coquete com o atraso do Brasil (por exemplo, por Diogo Mainardi).

Entendo, em parte, as críticas contra o universo reduzido que aparece na obra de Rosa. Mas acredito que essa crítica é excessivamente cosmopolita. Mainardi, por exemplo, coloca-se à distância, medindo o mérito de Rosa (que é imenso no panorama da literatura brasileira) a partir de parâmetros inadequados. Na arte, é bom avaliar o que o que foi feito e o que foi possível fazer. Rosa começou como poeta e contista e desenvolveu sua técnica "romanesca" a partir desses seus pendores predominantes. Seu Magma queria transformar a poesia popular em poesia popular-e-erudita, mas o próprio poeta julgou que essa tentativa redundara num beco sem saída. Dessa constatação e da grandeza de abandonar a poesia, nasceu uma nova maneira de contar, que enxerta o pendor lírico na prosa saborosa dos contistas (de Minas, mas também do Rio Grande do Sul), aliando o realismo muito concreto com fantasias amorosas e místicas e com o desejo de elevação metafísica. Tudo isso representa uma criação bastante voluntarista, a partir de dados históricos especificamente brasileiros. O gênero que Rosa criou e sua préhistória são muito distantes do romance (gênero europeu) propriamente dito - e Rosa o sabia, senão não teria dito que Grande Sertão: Veredas é mais uma 
lenda e "até um poema pudesse mesmo ser"... Essa observação assinala a diferença com os romances modernos de Proust e Henry James, de Joyce e de Musil. Esses representam a fina flor de um longo processo de fermentação artística e acúmulo intelectual, de uma "tradição formal": essa não consiste apenas em um desenvolvimento narrativo, mas na plasmação de hábitos comunicativos diversificados (uma multiplicidade de registros de expressão distintos e concorrentes) que não existia no Brasil de G. Rosa.

Os temas amorosos que Rosa escolhe, por exemplo, podem parecer limitados quando pensamos que, desde o século 18, o romance chamado "licencioso" integra os sentimentos e desejos desviantes na reflexão moral, força uma porta para um continente não tanto desconhecido, mas antes não falado: o mundo de emoções complicadas, dúbias e fora da teia dos discursos legítimos. Crébillon Fils é apenas um dos representantes dessa tradição de "libertinos" no século 18, Proust é o apogeu dessa tradição. Ambos são representantes de uma longa e lenta complexificação da arte narrativa, dos salões, do movimento dos escritores libertinos, dos desafios de centros como a corte de Versailles com seus satélites antagônicos (Port Royal, etc.). É absolutamente impossível julgar Rosa a partir desse tipo de parâmetro que pressupõe não só um mundo e seus discursos, mas um longo processo de ambientação mimética desses discursos na literatura.

Seria muito mais útil comparar Rosa com Göethe e os préromânticos alemães (Novalis e Rilke, por exemplo, cujos "Hinos à Noite" e "O Porta-Estandarte..." ecoam nas narrativas rosianas), do que do romance moderno a partir de Proust e Joyce. Isso não significa que Rosa cultive o "atraso" - qualquer sentido que possa ter esse termo. Ele faz o que é possível e necessário dentro de determinado contexto. Isso aconteceu também em outras culturas. Göethe, por exemplo, que tanto fez para alçar a literatura alemã a certo patamar, também foi alvo de remoques sarcásticos que o censuraram como provinciano e sentimental. Sempre é possível criticar - até um monumento literário como Göethe - quando se escolhe uma perspectiva perspicaz, por exemplo, parâmetros franceses para um narrador alemão. Barbey d'Aurevilly, grande narrador, embora quase desconhecido no Brasil, assumiu, frente a Göethe, o papel dos que, com mais ou com menos humor, riram do que chamam às vezes de "matutices sentimentais" do grande Rosa: escreveu que "morre de tédio" com os romances de Göethe, "obusado" [metralhado] pelos clichês das suas figuras femininas, pela repetição do "éternel tricot" que 
parodia, evidentemente, o "eterno feminino", a representação goetheana do feminino que os alemães apreciaram como algo inimitável e preciosíssimo. Pessoalmente gosto dessas vozes dissonantes que aguçam o olhar. Mas acho importante também ver qual era o projeto de Rosa: a tentativa de reforçar os elementos propícios para criar uma tradição autenticamente brasileira. No Brasil, o problema da expressão literária de sentimentos interiorizados, das perversões, das mil dobras interiores da alma, surge abruptamente, sem o preparo lento, no século 20. Mario de Andrade, por exemplo, no romancenovela Amar, verbo intransitivo toca na diferença abissal que separa a sensibilidade amorosa e estética alemã (Fräulein) da do adolescente paulista. Mas todo esse problema se resume em uma curta cena, numa alusão importante, ainda que germinal, às atitudes totalmente diversas (brasileira e alemã) diante da natureza, do corpo físico, do corpo feminino. Ainda nos anos 20, esses problemas de adequar forma e conteúdo da interioridade são pouco elaborados - Clarice, Osman Lins, Mario de Andrade, Oswald de Andrade, e muitos outros se debruçam sobre a conquista das formas especificamente brasileiras de sutilezas que já fazem parte de uma longa tradição européia.

Esse longo desvio nos leva ao problema do engajamento político. Rosa se sentiu um autor muito engajado com a coisa política latu sensu. De certa forma, ele tinha uma posição bastante próxima de um Hölderlin ou de Musil que eram muito sinceros na sua convicção de que um artista é "político" e "engajado" na medida em que cuida seriamente da sua linguagem, do refinamento estilístico de sua expressão, enfim, levando a sério sua arte. As implicações políticas da literatura - desde o surgimento das literaturas vernáculas, nas quais a mera escolha do francês ou do português (em vez do latim) já tinha implicações sociais, religiosas e políticas - surgiram, durante séculos, da complexidade da cultura, das diferenças de expressão dos diversos estratos sociais, grupos de interesse em conflito, etc. Quem lê uma boa biografia de Shakespeare (por exemplo, a de Steven Greenblatt) conhece bem a plasmação desses conflitos estilísticos nos sermões e correspondências, provérbios e contos, nos jogos de mistérios e as nas tragédias que preparam o salto estilístico e a densidade da arte de Shakespeare. Acho legítimo para um artista não querer ser mais político do que Shakespeare, mantendo-se no limiar da arte, recorrendo somente a sugestões, analogias. A Rosa pareceria de mau gosto e artisticamente ilegítimo entrar no domínio dos conceitos e 
das ideologias. Ainda mais na sociedade na qual ele vive: carente de formas de expressão, de práticas e instituições com modos e estilos próprios. ${ }^{1}$

Certamente não é por acaso que Rosa escolhe o mundo sertanejo, o tema do pacto como veículos para a fusão de elementos vivos da cultura brasileira. As realidades políticas que ele reelabora - através das formas de expressão autênticas do Brasil (poesia popular de grande qualidade, tradição de contistas populares e eruditos e da reflexão ensaística desde Euclides da Cunha) - são os problemas dos pensadores do Brasil: o caráter melancólicosaudoso com sua oscilação entre volúpia e violência; a cordialidade com suas cumplicidades malignas que permeiam todos os estratos da sociedade; o forte imaginário do clã (parental e eleitoral), etc.

Rosa percebeu muito claramente os desafios históricos da literatura brasileira e tinha um extraordinário dom artístico que lhe permitia expressar - numa nova forma! - alguns dos elementos essenciais da cultura luso-brasileira: a saudade, o pendor lírico, o fundo melancólico, o ativismo pragmático. Acho que isso é mais do que se possa esperar de um artista. Cabe à crítica descrever detalhadamente como essa fusão foi possível e como o valor de cada tema muda em qualidade e expressividade nessa fusão. O saudosismo é um tema constante na literatura luso-brasileira, a crítica do caráter melancólico-sensual é o tópico predileto dos ensaístas; logo antes de Rosa começar seu romance, Sérgio Buarque de Holanda e Gilberto Freyre elaboram a cordialidade como o traço distintivo de certa sociabilidade rural ou como um traço do caráter nacional. Rosa absorve muitas dessas idéias, mas ele desloca esses motivos completamente e lhes confere uma força e um impacto outros. Ele desvincula o saudosismo da sua expressão lírica no poema - e isso significa romper com o gênero mais valorizado no plano social e no plano artístico - transportando toda essa temática para o gênero narrativo. A

1. Na Europa, os salões (literários e mundanos) não se confundiam necessariamente com os salões políticos, de forma que a arte e a literatura podem ser o palco no qual ocorrem subliminarmente conflitos através do emprego de estilos distintos. Essa cultura sofre, mais tarde, a pressão de novas formas da cultura urbana popular: as vanguardas exploram, desde o século 19, o que era considerado de vulgar, perverso, banal, decadente, os choques entre expressões e sentimentos oriundos de extratos distintos da sociedade e, por final, a irrupção da vulgaridade industrial, dos novos meios de comunicação, criando uma sensibilidade paralela, totalmente descolada daquela "artesania" cultural que requer formação, muita leitura, aprendizado de procedimentos técnicos 
criação de uma narrativa híbrida - o "romance" como lenda e poema - permite articular também o avesso da saudade e do remorso diante dos defeitos do caráter nacional alfinetados pelos ensaístas. Somente na forma narrativa foi possível diminuir a carga sentimental do saudosismo e dar voz às facetas inquietantes de ódio e ressentimento que se alojam nas máscaras cordiais e sentimentais. Portanto, há uma série de temáticas aparentemente estilísticas, políticas e sociais que são aprofundadas de tal maneira que emerge a aura de uma psicologia profunda e de uma trajetória metafísica.

Por isso, parece-me impossível clivar o sentido social e político da descrição dos procedimentos artísticos. Acho que a obra de Rosa não se presta a uma clivagem da interpretação em campos espirituais, estéticos e ideológicos. A escola de Antônio Cândido foi muito meritória; ela forneceu uma crítica que dispunha dos dados sociais e políticos situando o contexto dessa obra. Walnice Nogueira Galvão, Roberto Schwarz, F.L.Chaves e H. Dacanal entre muitos outros exploraram essa contextualização histórica, social e ideológica. E recentemente, surgiram trabalhos mais específicos. Luiz Roncari levantou uma série de semelhanças entre as estruturas imaginárias da narrativa Rosiana e os conceitos forjados por um ensaísta como Oliveira Vianna. Acho realmente importante esse levantamento de semelhanças estruturais precisas. Susana Lages explorou o tema fundador da saudade luso-brasileira.

Meu novo livro "Desenveredando Rosa" retoma esses eixos diversos, focalizando o impacto, direto ou indireto, que Euclides da Cunha, G. Freyre, S.B. de Holanda e Oliveira Vianna, Paulo Prado e outros tiveram sobre a arte de G. Rosa. Não basta mais afirmar, repetindo a estereotipia do "retrato", da "imago" reveladora da nacionalidade ou da "crítica" anunciadora, tão genérica e forçada, que GSV seria um "retrato do Brasil". A crítica hoje tem de descrever como a literatura concilia dialeticamente os elementos heterogêneos de sua história. Não é suficiente afirmar que Grande Sertão: Veredas integra todas as dimensões (metafísicas, religiosas, sociais e políticas, etc.). Por essa razão, meu novo livro analisa as técnicas literárias, as influências de autores brasileiros e estrangeiros (Freyre, Euclides, Oliveira Vianna, Paulo Prado, Machado, Flaubert, Dostö̈evsky, Goethe, Novalis, Rilke, etc.). Essas análises mostram como as influências são transformadas e como se refletem no tecido das narrativas de Rosa. Na literatura, a realidade é filtrada em canais sutis e sinuosos, cada imagem é mais do que a alegoria de uma realidade política ou social, geográfica ou psicológica, espiritual ou religiosa. Quem 
declara que a cena do pacto seria uma representação da modernização no Brasil, teria que explicar como e onde, com quais elementos ocorre essa modernização. A critica literária tem que explicar como um tema tão anacrônico pode ressurgir na literatura moderna. Ou por que sua elaboração míticosimbólica, que regride para representações panteístas pagãs, salpicadas com sugestões freudianas, pode preencher essa tarefa. Procurei mostrar, no meu novo livro sobre a obra rosiana quais são as imagens, as técnicas romanescas e líricas, os artifícios épicos e dramáticos que realmente integram as dimensões diversas.

A primeira parte de Desenveredando Rosa (cerca de 220 páginas) precede o texto revisado de Os descaminhos do demo (publicado em 1992 e agora reeditado). Não alterei significativamente esse último texto, apenas escrevi um novo prefácio que delineia claramente o meu método de então. Naquela época, recém chegada no Brasil e ainda absorvendo o choque cultural, Grande Sertão Veredas foi o meu "objeto transicional" - assim Melanie Klein chama os ursos, fraudas, travesseiros nos quais as crianças se agarram numa certa idade para suportar a separação da mãe. Rosa trazia os ecos das literaturas que mais amava e me permitia conhecer o Brasil - os Brasis - numa dimensão transfigurada, sem os atritos do dia-a-dia, sem as reservas e as críticas que os brasileiros me expunham constantemente. Foi uma mistura de amor ingênuo e de decisão astuta que me levaram a privilegiar a trama mítica (indo-européia e afro-brasileira). A primeira metade do novo livro e o novo prefácio completam essa análise e contextualizam melhor a obra Rosiana.

Abstract: Reflections upon "Grande Sertão: veredas", by Guimarães Rosa, with an approach that emphasizes the literary gender, the political engagement, and philosophical adbesion.

Key words: literary reflections, philosophical, political. 